\section{Martian Residents: Mass Media and Ramsar High Background Radiation Areas}

\author{
Abbasi S. ${ }^{\oplus}$, Mortazavi S. A. R. ${ }^{2}$, Mortazavi S. M. J. ${ }^{1,3 * \odot}$
}

\begin{abstract}
Considering current controversies regarding the health effects of low doses of ionizing radiation, study of the high background radiation areas such as Ramsar, Iran can help scientists better evaluate the validity of linear no-threshold (LNT) hypothesis. Ramsar is a coastal city in northern Iran with some areas known to have the highest levels of natural background radiation in the world. The mean annual dose of the residents of high background radiation areas (HBRAs) of Ramsar is 10 times higher than the public dose limit recommended by the ICRP ( $1 \mathrm{mSv} / \mathrm{year})$ and a proportion of the residents receive annual doses as large as $260 \mathrm{mSv}$ (13 times higher than the occupational dose limit recommended by the ICRP). A report published in Popular Science proclaims that background radiation in Ramsar approaches that of the Martian surface. However, estimates show that the maximum annual radiation dose in HBRAs of Ramsar can be much higher than that of the Martian surface ( $260 \mathrm{mGy} / \mathrm{y}$ vs $76 \mathrm{mGy} / \mathrm{y})$. Furthermore, a Guardian report introduces Talesh Mahalleh, a district in Ramsar, as an inhabited area with the highest levels of natural radioactivity in the world and $\mathrm{C}$ Net claims that the best Mars colonists may come from places like Iran and Brazil. In spite of current concerns, nearly all residents still live in their paternal dwellings and there are not consistent reports on any detrimental effects. It is worth noting that, due to small sample size, to draw a firm conclusion about the health effects of high level natural radiation in Ramsar, in particular about the cancer risk, current information is not sufficient and further studies are needed.
\end{abstract}

Citation: Abbasi S, Mortazavi S. A. R, Mortazavi S. M. J. Martian Residents: Mass Media and Ramsar High Background Radiation Areas. $J$ Biomed Phys Eng. 2019;9(4):483-486. https://doi.org/10.31661/jbpe.v0i0.1138.

\section{Keywords}

Background Radiation • Iran • Linear No-Threshold Theory (LNT) • Radiation Protection • Natural Radiation

\section{Introduction}

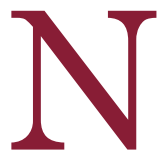

ot only life evolved in a radiation field that was much more intense than today but high level natural radiation was an essential part of life. The ambient dose rates dropped by a factor of 10 since life first evolved. In early days of life high levels of background radiation is accounted for up to $33 \%$ of mutations to the first life forms [1] while background radiation presently accounts only for $1-6 \%$ of mutations. Today, areas with high background radiation (HBRAs) are found in many places such as
${ }^{1}$ Medical Physics Department, School of Medi-

cine, Shiraz University

of Medical Sciences,

Shiraz, Iran

${ }^{2}$ Student Research

Committee, School of

Medicine, Shiraz Univer-

sity of Medical Sciences,

Shiraz, Iran

${ }^{3}$ Diagnostic Imaging

Department, Fox Chase

Cancer Center, 333 Cott-

man Avenue, Philadel-

phia, PA 19111, USA

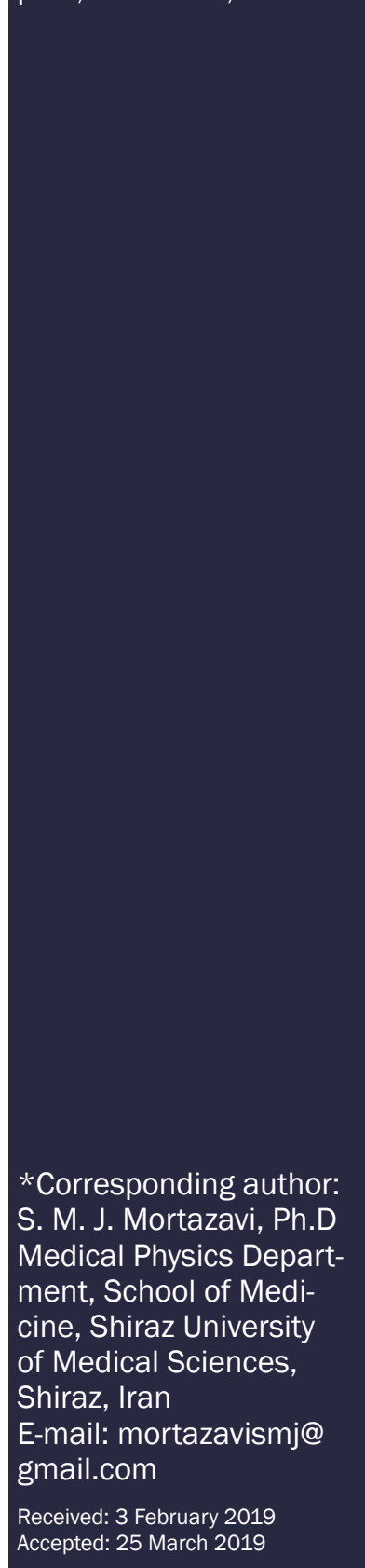


Ramsar, Iran; Yangjiang, China; Kerala, India; and Guarapari, Brazil. According to UNSCEAR 2000 report [2], Ramsar, a seaside vacation resort on the southern coast of the Caspian Sea, has inhabited areas with the highest known natural radiation levels in the world. Radiation levels on Earth vary by at least two orders of magnitude (e.g. Ramsar with a max dose of $260 \mathrm{mGy} / \mathrm{y}$ compared to Denmark with a $\max 0.61 \mathrm{mGy} / \mathrm{y}$ ) [3]. In HBRAs of Ramsar, gamma radiation levels are up to about $20 \mathrm{mSv} / \mathrm{hr}$ at waist level and a population of about 2000 lives in this area. Annual exposure levels range from about 20 to $260 \mathrm{mGy}$ for people in hot areas. Talesh Mahalleh, a well-known district in Ramsar has been introduced as the most naturally radioactive inhabited area in the world [3].

\section{Martian Surface and Ramsar}

Charlie Wood in a report published by Popular Science in 2018 [4] compares the radiation dose in high background radiation areas of Ramsar with those of the Martian surface "Fortunately, and inexplicably, cancer there occurs at similar rates to nearby areas, despite background radiation approaching that of the Martian surface". Although this report has proclaimed that background radiation in Ramsar approaches that of the Martian surface, studies shows that the maximum annual radiation dose in HBRAs of Ramsar can be much higher than the Martian surface.

\section{The Most Radioactive City}

In 2015, the Guardian published a report entitled What's the most radioactive city? [5] This report states "The city of Ramsar, Iran has such high natural background radiation levels that scientists have recom- mended that the 32,000 residents relocate". This report also introduces Talesh $\mathrm{Ma}$ halleh, a district in Ramsar, as an inhabited area with the higheslevels of natural radioactivity in the world "Its neighbourhood of Talesh Mahalleh, the most naturally radioactive inhabited area in the world, is under long-term study". However, this report has some shortcomings. For example, while the population of HBRAs of Ramsar is about 1000-2000(1), it is reported 32,000 in this report. Moreover, as discussed in the following sections, relocation is not supported by current findings.

Mars Colonists Could Come from Ramsar

"Why the best Mars colonists could come from places like Iran and Brazil?" This is the title of a report published by $\mathrm{C} \mathrm{Net}$ [6]. This reports states "For years now, scientists have been studying residents of Ramsar, a town in northern Iran that is believed to have the highest levels of naturally occurring background radiation for an inhabited area".

Should Local People Be Afraid of Radiation?

The ICRP limits for general public and radiation workers are 1 and $20 \mathrm{mSv}$ per year, respectively. The annual effective dose for the residents of HBRAs of Ramsar is up to 13 times higher than the limit for occupational exposures. Given this consideration, a key question is whether local people should be afraid of radiation? It is worth noting that scientist believe that exposure to background radiation does not increase the risk of either acute effects or cancer "Background radiation has never been shown to unequivocally cause acute 
or latent disease, such as cancer (Hall and Ciaccia 2005)" [7]. Moreover, there are reports indicating reduced rates of cancer in the residents of areas with elevated levels of natural radiation "Reduced cancer occurrence was reported since decades ago for HBRAs (Frigerio et al. 1973, Cohen 1995, Aliyu and Ramli 2015, Mortazavi et al. 2005, Nair et al. 2009, Sun et al. 2000)" [7]. Therefore, if exposure of residents to radiation doses of a few hundred $\mathrm{mSv}$ per year is detrimental to their health causing increased risk of cancer, it should be evident in these people. In spite of this, nearly all residents still live in their paternal dwellings and there are not consistent reports on any detrimental effects [8-9]. we should consider that only a very small part of the Ramsar population is living in high background radiation areas. Therefore, due to small sample size, a firm conclusion about the cancer risk cannot be drawn.

\section{Conclusion}

The mean annual dose of the residents of high background radiation areas of Ramsar is 10 times higher than the public dose limit recommended by the ICRP and a proportion of the residents receive annual doses as large as $260 \mathrm{mSv}$ that is 13 times higher than the occupational dose limit recommended by the ICRP. The latter dose is much higher than that of the Martian surface. High background radiation areas of Ramsar has increasingly attracted attention of the media. Despite there is not consistent reports on any detrimental effects, to draw a firm conclusion about the health effects of high level natural radiation in Ramsar, in particular about the cancer risk, current information, at least to some extent due to small sample size, is not sufficient and fur- ther studies are needed.

\section{Conflict of Interest}

Authors declare no competing interests.

\section{References}

1. Karam PA, Leslie SA. Calculations of ba round beta-gamma radiation dose through geologic time. Health Phys. 1999;77:662-7. doi: 10.1097/00004032199912000-00010. PubMed PMID: 10568545.

2. Radiation UNSCotEoA. Sources and effects of ionizing radiation: sources. New York: United Nations Publications; 2000.

3. Ghiassi-nejad M, Mortazavi SM, Cameron JR, Niroomand-rad A, Karam PA. Very high background radiation areas of Ramsar, Iran: preliminary biological studies. Health Phys. 2002;82:87-93. doi: 10.1097/00004032-200201000-00011. PubMed PMID: 11769138.

4. Charlie Wood [Internet]. The ExoMars spacecraft measured radiation in deep space to help keep future astronauts safe. [Cited September 25, 2018]. Available from: https://www.popsci.com/exomarsradiation-astronauts

5. The Guardian [Internet]. What's the most radioactive city? [Accessed on Feb 3, 2019] Available from: https://www. theguardian.com/cities/2015/may/15/ what-most-radioactive-city-chernobylfukushima

6. Eric Mack [Internet]. Why the best Mars colonists could come from places like Iran and Brazil. [Accessed on Feb 3, 2019]. Available from: https://www.cnet. $\mathrm{com} /$ news/why-the-best-mars-colonistscould-come-from-places-like-iran-andbrazil/

7. Dobrzynski L, Fornalski KW, Feinendegen LE. Cancer Mortality Among People Living in Areas With Various Levels of Natural Background Radiation. Dose Response. 2015;13:1559325815592391. doi: 10.1177/1559325815592391. PubMed PMID: 26674931; PubMed Central PMCID: PMC4674188. 
8. Mortazavi S, Mozdarani H. Is it time to shed some light on the black box of health policies regarding the inhabitants of the high background radiation areas of Ramsar. Int J Radiat Res. 2012;10:111-6.
9. Mortazavi S, Mozdarani H. Non-linear phenomena in biological findings of the residents of high background radiation areas of Ramsar. Int $J$ Radiat Res. 2013;11:3-9. 